\title{
Effects of Nonuniform Blade Pitch on the Flow Through an Annular Turbine Nozzle
}

\author{
RAINER KURZ \\ Solar Turbines Incorporated, San Diego, California
}

\begin{abstract}
This paper discusses flow measurement results both upstream and downstream of a transonic annular gas turbine nozzle with a nonuniform pitch. The downstream measurements are performed in the plane where the leading edge of the rotor blade is located in the gas turbine. The experiments were performed using total pressure probes and wall static pressure taps. The pitch variation modifies the flow field both upstream and downstream of the nozzle, although the experiments show that the effect is localized to the immediate neighborhood of the involved blades. The effects on the wakes and on the inviscid flow are discussed separately. The mean velocities show a strong sensitivity to the changes of the pitch, which is due to a potential flow effect rather than a viscous effect.
\end{abstract}

Key Words: Nonuniform pitch; Turbine; Losses; Excitation; Transonic flow

\section{INTRODUCTION}

$\mathbf{N}_{\mathrm{i}}$ onuniform pitched gas turbine stators are used both in thermal and hydraulic turbomachines to reduce the excitation of the downstream rotor.

The examined nozzle is a production nozzle of a small gas turbine and is operated at transonic flow conditions. The blades are arranged in a way that 11 nozzles with a narrow pitch are followed by one nozzle with an intermediate pitch and another 11 nozzles with a wide pitch (Fig. 1).

The nonuniformity of the flow behind turbine nozzles is due to wakes, inviscid effects from turning (Gloger [1979]) and shock waves. All of these effects disappear far downstream from the nozzle, but are usually rather strong in the rotor plane. Fig. 2 shows the reduction of the fluctuations due to wakes and inviscid effects with the distance from the trailing edge of the nozzle. The inviscid fluctuations are described by

$$
\Delta M^{*}=\left(M_{1 \text { smax }}^{*}-M^{*}{ }_{1 \text { smin }}\right) / \bar{M}^{*}{ }_{1 s}
$$

whereas the fluctuations due to wakes can be described by

$$
\Delta M^{*}=\left(M_{1 s}^{*}-M_{1}^{*}\right)_{m a x} \bar{M}_{1 s}^{*}
$$

In terms of measured data, the static pressure fluctuations represent the inviscid fluctuations. The total pressure fluctuations are linked to the fluctuations created by wakes and shocks.

As can be observed from Fig. 2 and also from the measurements of Gloger [1979], and Korakianitis [1993], both effects have approximately the same magnitude in the rotor blade leading edge plane.

For conventional configurations with uniformly pitched blades, all these disturbances will appear periodically (e.g. Arndt, [1991]) and thus will excite the following rotor blades with a frequency that is proportional to the rotor speed and the number of nozzle blades.

For nozzles with a nonuniform pitch, described in Fig. 1 , the excitation of the rotor blades is nonperiodic.

This paper examines the effect of a sudden change in pitch on the flow field upstream and downstream and the losses of the nozzle.

\section{TEST PROGRAM}

\section{Test Facility}

The tests were conducted at the annular cascade test facility of the "Laboratorium fuer Stroemungsmaschinen" at the University of the German Armed Forces 
(Fig. 3). The test facility air is delivered by a $1 \mathrm{MW}$ radial compressor and blows into the atmosphere with the nozzle inlet total temperature kept constant using a water cooler.

\section{Test Configuration}

A production turbine nozzle with nonuniform pitch (Fig. 1 and Table 1) was mounted in a test rig that allowed static and total pressure measurements in front and downstream of the nozzle. The blades of the nozzle are arranged in a way that 11 channels with a narrow pitch (pitch-to-chord ratio at mid-span $\mathrm{t}_{\mathrm{n}} / \mathrm{c}=0.771$ ) are followed by one channel with an intermediate pitch $\left(\mathrm{t}_{\mathrm{i}} / \mathrm{c}\right.$
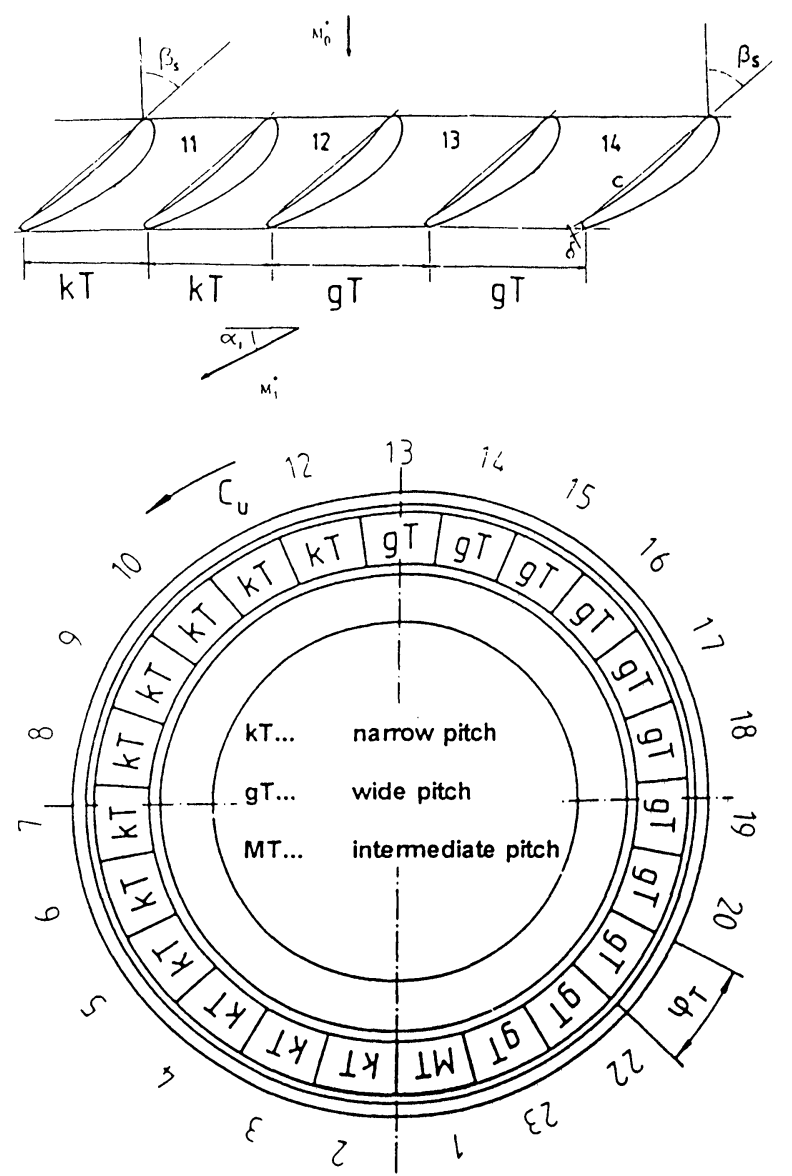

Blade circumferential angle for one pitch $\varphi_{T}$

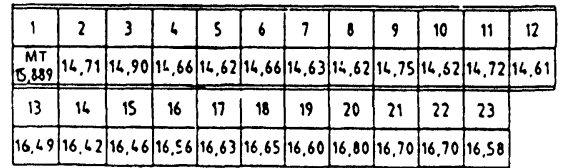

FIGURE 1 Turbine nozzle with nonuniform pitch.

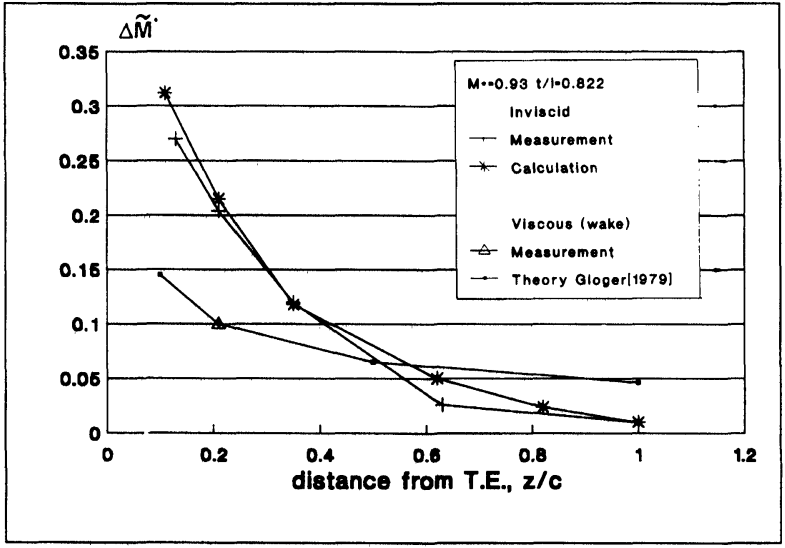

FIGURE 2 Decrease of inviscid and viscous flow fluctuations behind the trailing edge of the turbine cascade. Measurement data from Kurz [1991].

$=0.839)$ and another 11 channels with a wide pitch $\left(\mathrm{t}_{\mathrm{w}} / \mathrm{c}\right.$ $=0.877$ ).

The hub section downstream of the nozzle was designed according to the recommendations of Dejc and Trojanovskij [1973] to obtain a stable, nonseparated flow downstream of the nozzle.

Measurement planes of the described arrangement are at $\mathrm{z} / \mathrm{c}=0.15$ upstream of the leading edge of the nozzle

TABLE 1

Nozzle Design Data

\begin{tabular}{|c|c|c|c|c|}
\hline Inlet flow angle & & $\alpha_{0}$ & $=$ & $90.0^{\circ}$ \\
\hline Exit flow angle (design) & & $\alpha_{1}$ & $=$ & $26.0^{\circ}-26.9^{\circ}$ \\
\hline Number of blades & & $\mathrm{N}_{\mathrm{b}}$ & $=$ & 23 \\
\hline Hub diameter (exit) & & $\mathrm{r}_{\mathrm{h}}$ & $=$ & $127.90 \mathrm{~mm}$ \\
\hline Shroud diameter (exit) & & $r_{s}$ & $=$ & $157.40 \mathrm{~mm}$ \\
\hline Blade height (exit) & & $\mathrm{H}$ & $=$ & $14.75 \mathrm{~mm}$ \\
\hline Aspect ratio (exit) & & $\mathrm{H} / \mathrm{c}$ & $=$ & 0.625 \\
\hline Trailing edge thickness & & $\delta_{\mathrm{te}} / \mathrm{c}$ & $=$ & 0.04 \\
\hline Average blade center angle & wide & $\varphi_{\mathrm{w}}$ & $=$ & $16.6^{\circ}$ \\
\hline & int. & $\varphi_{\mathrm{i}}$ & $=$ & $15.9^{\circ}$ \\
\hline & narrow & $\varphi_{\mathrm{n}}$ & $=$ & $14.7^{\circ}$ \\
\hline Average Pitch-to-chord ratio & & & & \\
\hline at mid-span & wide & $t_{w} / c$ & $=$ & 0.771 \\
\hline & int. & $t_{i} / c$ & $=$ & 0.839 \\
\hline & narrow & $t_{n} / c$ & $=$ & 0.877 \\
\hline $\begin{array}{l}\text { Distance of the upstream me } \\
\text { plane from the leading edge }\end{array}$ & Irement & $\mathrm{z} / \mathrm{c}$ & $=$ & 0.15 \\
\hline $\begin{array}{l}\text { Distance of the downstream } \\
\text { plane from the trailing edge }\end{array}$ & urement & $\mathrm{z} / \mathrm{c}$ & $=$ & 0.213 \\
\hline
\end{tabular}

TABLE 2

Nozzle Operating Conditions

\begin{tabular}{llll}
\hline Reynolds number & $\mathrm{Re}$ & $=$ & 700,000 \\
Exit Laval number & $\overline{\mathrm{M}}_{1}{ }^{*}$ & $=$ & 0.91 \\
\hline
\end{tabular}


a)

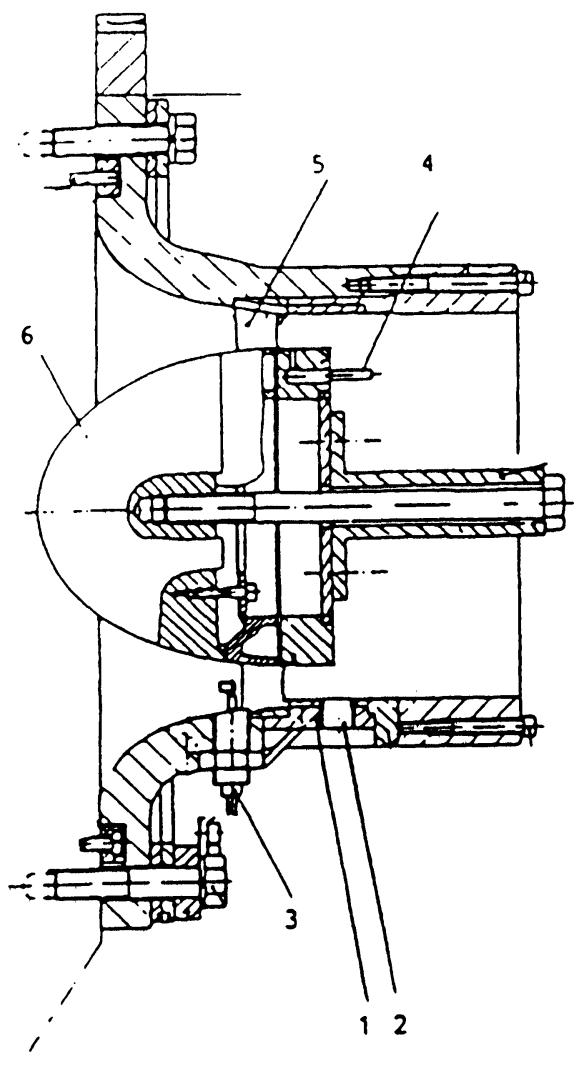

1 movable adaption

$2 \quad$ Kiel probe $\left(p_{t 1}\right)$ or static pressure tap $\left(p_{1 s}\right)$ in fixture as in \#3

3 Kiel probe $\left(p_{t 0}\right)$ or static pressure tap

48 Static pressure taps circumferential $\left(p_{1 h}\right)$ to be moved relative to \#5

5 Turbine nozzle

6 Hub

b)

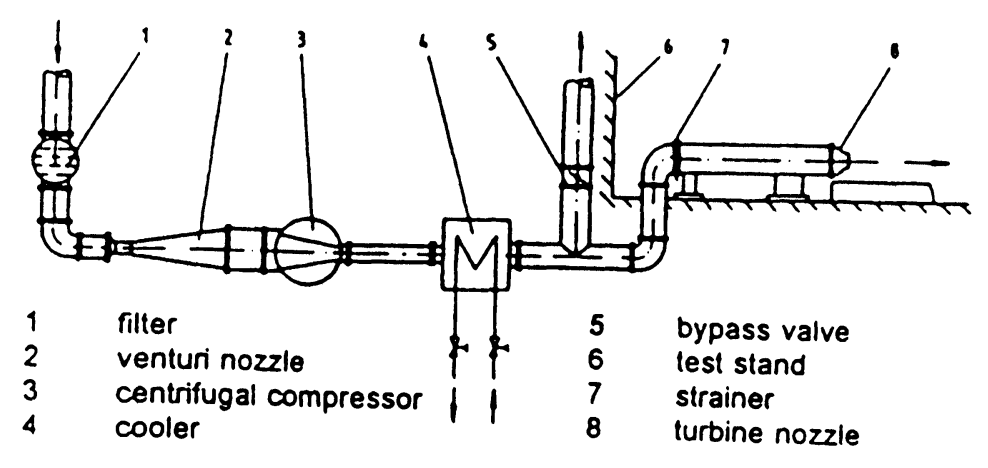

FIGURE 3 Test facility for the turbine nozzle.

blade and at $\mathrm{z} / \mathrm{c}=0.213$ downstream of the trailing edge. The downstream measurement plane was the plane, where the leading edge of the rotor blade is located in the gas turbine.

Data from a linear cascade with the same blade profiles was obtained from the high speed cascade wind tunnel of the same laboratory. Measurement procedures, details about the Laser-2-Focus measurements and a facility description are documented in Kurz [1991] and Kurz [1992]. 


\section{Instrumentation}

The total pressure measurements were carried out at mid-span $\mathrm{h} / \mathrm{H}=0.5$ with a Kiel probe which could be moved in circumferential direction. Static pressure instrumentation included eight wall taps in the hub and one wall tap in the shroud downstream of the nozzle, and one wall tap upstream of the nozzle. The movable wall tap in the shroud could be translated over about $3 \frac{1}{2}$ blade channels (Fig. 3, Item 2). As the nozzle could be turned independently of the measurement devices, pressure data was gathered at every circumferential position.

\section{DATA REDUCTION}

As discussed previously, static pressures were measured with tabs in the hub and the shroud of the cascade. The static pressure at mid-span was calculated using the radial equilibrium equation for a potential free vortex $\left(c_{u}\right.$ $r=$ const) and a constant density $\rho$ where

$$
p_{1 m}(\varphi)=p_{h}(\varphi)+\frac{\left(p_{s}(\varphi)-p_{h}(\varphi)\right)}{\left(1 / r_{h}{ }^{2}-1 / r_{s}{ }^{2}\right)}\left(1 / r_{h}{ }^{2}-1 / r_{m}{ }^{2}\right)
$$

and

$$
\bar{p}_{1 m}=\frac{1}{\varphi_{T}} \int_{\varphi=0}^{\varphi_{T}} p_{1 m}(\varphi) d \varphi
$$

Thus, a local enthalpy loss coefficient can be defined by

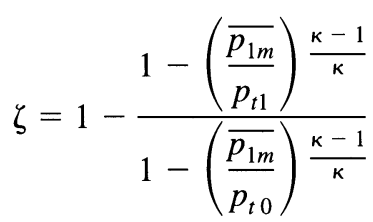

In the following sections, an averaged loss coefficient was used

$$
\zeta=\frac{1}{\varphi_{T}} \int_{\varphi=0}^{\varphi_{T}} \zeta(\varphi) d \varphi
$$

where the limits of the integration coincide with the geometric center of adjacent blade passages. Eq. (6) therefore represents the losses produced by one blade.

Static pressures are made nondimensional by introducing the Laval number

$$
M^{*}=\sqrt{\frac{\kappa+1}{\kappa-1}\left(1-\left(\frac{p}{p_{t}}\right)^{(\kappa-1) / \kappa}\right)}
$$

With the calculated static pressures at mid-span, it is also possible to determine the flow velocities at mid-span. The averaged velocities at mid-span are in good accordance with L-2-F measurements achieved for two of the blades.

\section{MEASUREMENT RESULTS}

\section{Inviscid Effects}

The shroud static pressures at the inlet (Fig. 4) presented in terms of the Laval number show, that the flow readjusts to the different width of the flow channels downstream. For the overall pressure ratio of the nozzle, the inlet velocity for the narrow passages is smaller than for the wider ones. This adjustment occurs in the area where the pitch changes and is complete within two passages to either side, although small fluctuations persist around most of the turbine nozzle.

Fig. 5 shows the inviscid flow fluctuations in the area where the pitch changes from wide to narrow. In conjunction with Fig. 7 it can be seen that the mean velocity in this area will be higher than for the wide or the narrow pitched area. All of the other channels are not affected. The same results were obtained both experimentally and theoretically by Kurz [1992] for a linear cascade.

The opposite change from narrow and intermediate to wide pitch (Fig. 6) together with Fig. 7 results in a lower mean velocity than for the adjacent wide and narrow pitched areas both in the hub and the shroud area.

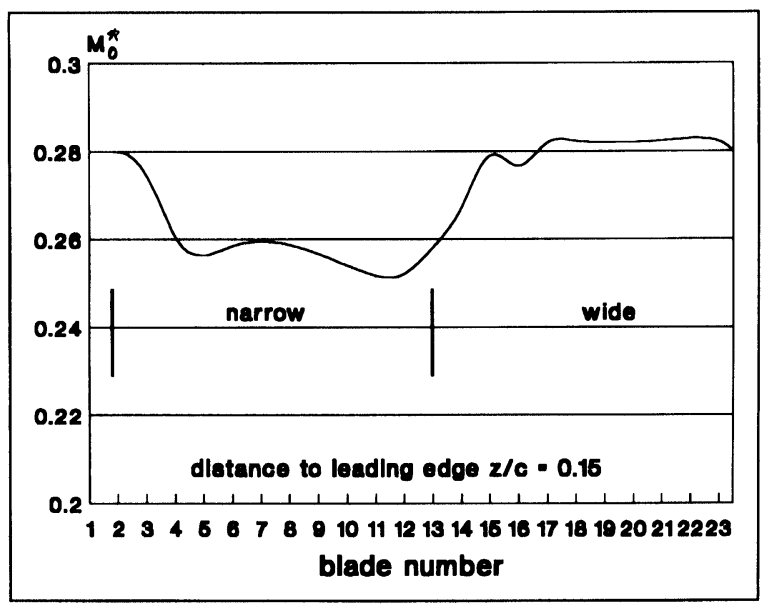

FIGURE 4 Circumferential distribution of the shroud static pressure (represented as Laval number) at the inlet. 


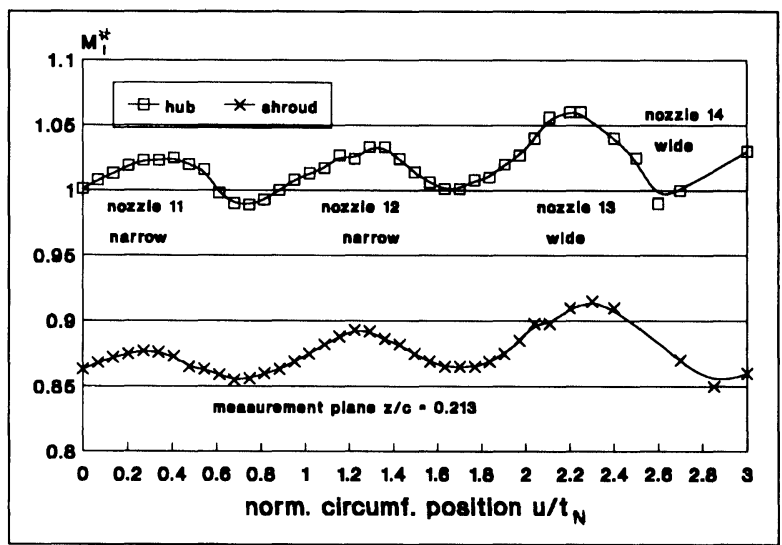

FIGURE 5 Circumferential distribution of the downstream wall static pressure (represented as Laval number) for nozzles 11, 12, 13, 14

It should also be mentioned that the flow fluctuations $\Delta \mathrm{M}^{*} / \overline{\mathrm{M}}^{*}$ are higher for the wide channel than for the narrow channel, which is in accordance with the theoretical results by Gloger [1979] and Kurz [1991]. Basically, the circulation around the blades with the wider pitch has to be higher, therefore resulting in greater fluctuations of the downstream flow.

\section{Blade Losses}

Fig. 8 shows the losses distribution caused by the blades of the nozzle at mid-span. The loss behavior of the blades where the pitch changes shows some slight deviations from the losses of the other blades. Results from Kurz [1992] for the linear cascade, showing that the nonuniform pitch does not lead to a much higher blade loss, is also valid for the current nozzle.

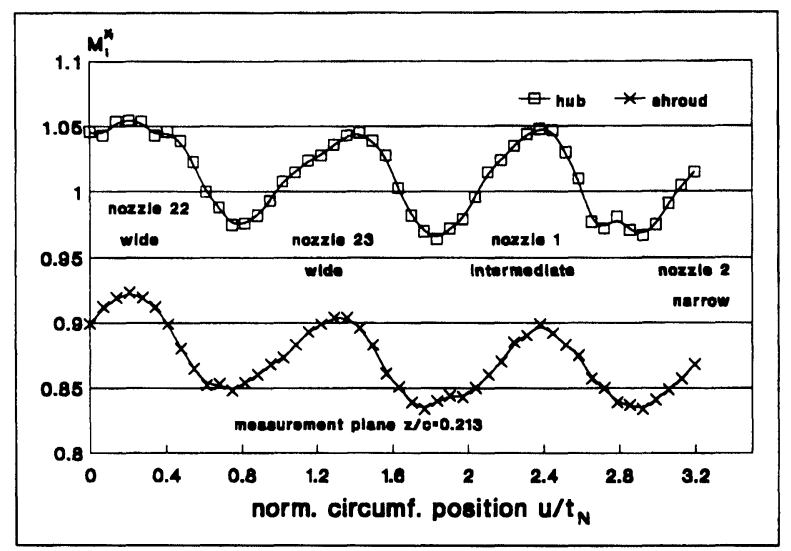

FIGURE 6 Circumferential distribution of the downstream wall static pressure (represented as Laval number) for nozzles 22, 23, 1.

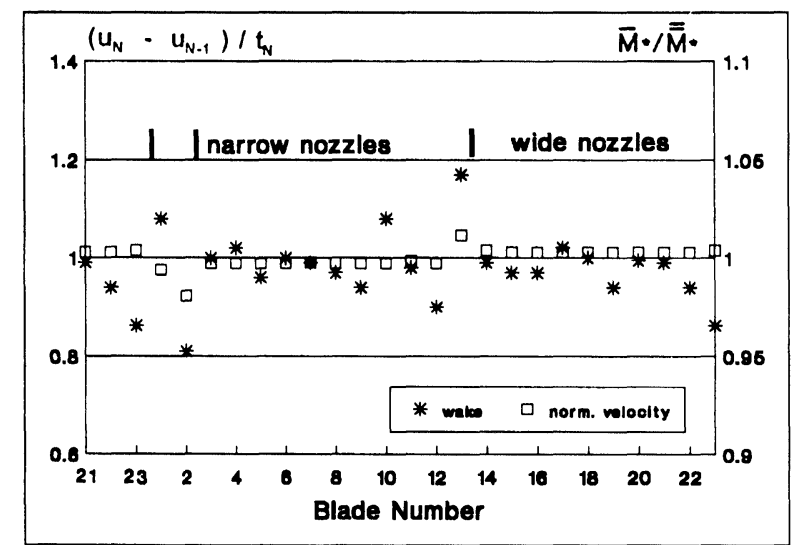

FIGURE 7 Nozzle blade wake positions and mean velocities.

The results for the losses obtained from the linear cascade (Kurz [1992]) with the same blades show a good correlation with the mid-span losses of the current nozzle.

In Fig. 8 velocity measurements obtained with the L2F measurement technique (Kurz [1991]) at $\mathrm{h} / \mathrm{H}=0.5$ are used to calculate the static pressure at midspan directly from measurements instead of using eq. (2). Fig. 8 shows the very small differences between the two methods.

Fig. 8 shows indeed an increase of the losses in the areas, where the pitch changes. Some of the other blades also show very high losses. It is believed, that the increased loss resulted from some damage sustained by the blades in question from earlier tests. Fig. 8 indicates the magnitude of the loss deviations due to the change in pitch as a minor issue.

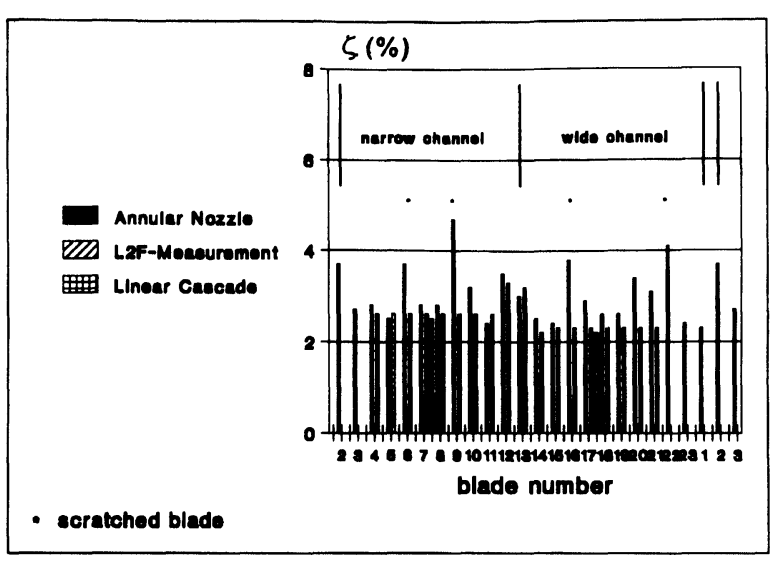

FIGURE 8 Blade loss distribution. 


\section{Wakes}

Of great interest for determining the exciting forces on the rotor blades is the circumferential position of the wake centers. In nozzles with uniform pitch the distance between wakes is equal to the blade pitch (e.g. Arndt [1991]). For the present configuration, however, the distance between the wakes is no longer equal to the pitch. Fig. 7 shows the relative circumferential distances $\mathrm{u}$ between the wake of blade $\mathrm{N}$ and the previous blade $\mathrm{N}-1$ normalized by the relevant pitch. The greatest deviations occur at the blades that separate a smaller pitch from a larger pitch. The deviations decrease with distance from these blades and become negligible after about 3 blades to each side. Fig. 7 also shows the pitch averaged Laval numbers, normalized by the mean midspan Laval number. As already mentioned in the discussion of Fig's. 5 and 6 , the velocities show deviations from the average in the areas where the pitch changes.

To determine the shape of the wakes, form factors of the wakes caused by the blades of the linear cascade (Kurz, 1991) were calculated. Compressible and incompressible form factors are defined by the expressions

$$
H_{12}=\delta / \theta
$$

where

$$
\begin{gathered}
\delta=\int_{-t / 2}^{+t / 2}\left(1-\frac{c_{1}}{c_{1 s}}\right) d y \\
\theta=\int_{-t / 2}^{+t / 2} \frac{c_{1}}{c_{1 s}}\left(1-\frac{c_{1}}{c_{1 s}}\right) d y
\end{gathered}
$$

and

$$
H_{12 c}=\delta_{c} / \theta_{c}
$$

with

$$
\delta_{c}=\int_{-t / 2}^{+t / 2}\left(1-\frac{\rho 1 c_{1}}{\rho_{1 s} c_{1 s}}\right) d y
$$

and

$$
\theta_{c}=\int_{-t / 2}^{+t / 2} \frac{\rho 1 c_{1}}{\rho_{1 s} c_{1 s}}\left(1-\frac{c_{1}}{c_{1 s}}\right) d y
$$

Fig. 9 shows that the wake of the blade, that separates the wide channel from the narrow channel has exactly the same shape as the wakes of the other blades. It is interesting that the incompressible form factor is not influenced by the increasing Laval number, whereas the compressible form factor is increasing. This effect needs some explanation.

Assuming a wake with a shape that can be described by an exponential velocity distribution

$$
c / c_{s}=1-\left(c_{0} / c_{s}\right) * \exp \left(-(y / b)^{2}\right)
$$

and using eq. (8), (9) and (10), the correlation between the shape factor $\mathrm{H}_{12}, \mathrm{c}_{0} / \mathrm{c}_{\mathrm{s}}$ and $\mathrm{b}$ can be described by

$$
\begin{aligned}
& c_{0} / c_{s}=2 *\left(1-1 / H_{12}\right) \\
& b=\frac{\delta}{\sqrt{4 \pi}\left(1-1 / H_{12}\right)}
\end{aligned}
$$

with

$$
\delta=(\zeta * t) /\left(1+1 / H_{12}\right)
$$

for $\mathrm{H}_{12}$ close to one.

Establishing this, we can also calculate $\mathrm{H}_{12 \mathrm{c}}$ from Eq. (9), using the known velocity distribution to calculate the density $\rho$ under the assumption of constant static pressure and total temperature across the wake.

The ratio between the compressible and the incompressible form factor $\mathrm{H}_{12 c} / \mathrm{H}_{12}$ depends only on the Laval number and the incompressible form factor. However, test calculations show, that the influence of $\mathrm{H}_{12}$ is minimal. The correlation between $\mathrm{H}_{12 \mathrm{c}}$ and $\mathrm{H}_{12}$ can be described by

$$
H_{12 c} / H_{12}=0.34 * M^{*}{ }^{2}+1
$$

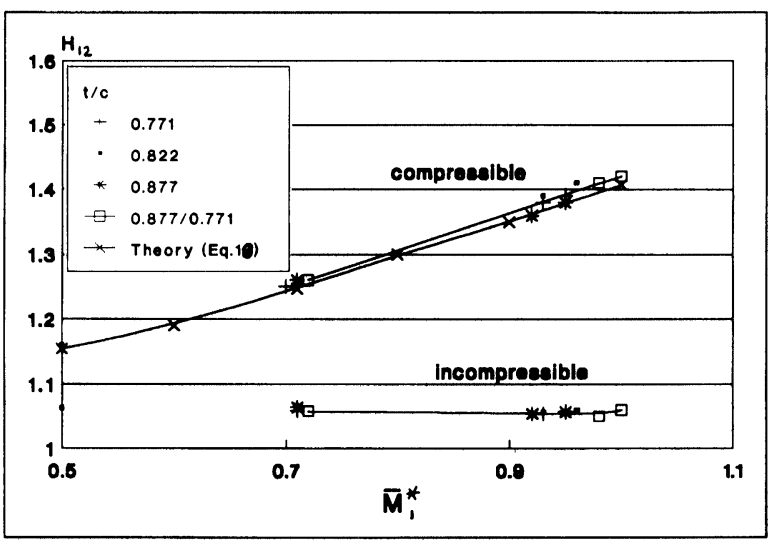

FIGURE 9 Form factors $\mathrm{H}_{12}$ of the wakes for the linear cascade. 
This curve is also shown in Fig. 9. It shows the exact agreement between the measured results and the theoretical approach.

\section{CONCLUSIONS}

A sudden change in blade pitch modifies the flow field both upstream and downstream of the nozzle. The present study shows that the influence of the change in the pitches is limited to the immediate neighborhood of the pitch variation.

The form factor of the wakes is not influenced by the nonuniform pitch, but the location of the wake centers is modified such that the spacing between the wake centers is no longer equal to the pitch.

Experimental results show that the mean velocities in the area where the pitch changes get increased for the change from wide to narrow pitch and get decreased for the change from narrow to intermediate and wide pitch. This is believed to be an inviscid effect.

The results of this investigation are not only of interest for the intended application of nonuniformly pitched nozzles in turbines, but also for the determination of the effects of misaligned blades due to manufacturing tolerances.

\section{Acknowledgements}

The investigation described in this paper was initiated and supported by KHD Luftfahrttechnik (now BMW-Rolls Royce Aeroengines) and the German Ministry of Defense. The measurements were conducted at the "Laboratorium fuer Stroemungsmaschinen" of the University of the German Armed Forces in Hamburg.

The author wishes to thank Andreas Czerwinski, Werner Clemens and Angelo Bauer for their help in accruing the data and Renee Widin for her help with the manuscript.

\section{Nomenclature}

$\begin{array}{ll}a & =\text { speed of sound } \\ c & =\text { blade chord } \\ c & =\text { velocity } \\ H & =\text { blade height } \\ H_{12}=\delta / \theta & =\text { form factor }(\text { Eq. }(8)) \\ H_{12 c}=\delta_{c} / \theta_{c} & =\text { compressible form factor }(\text { Eq. }(11)) \\ h & =\text { distance along blade height }\end{array}$

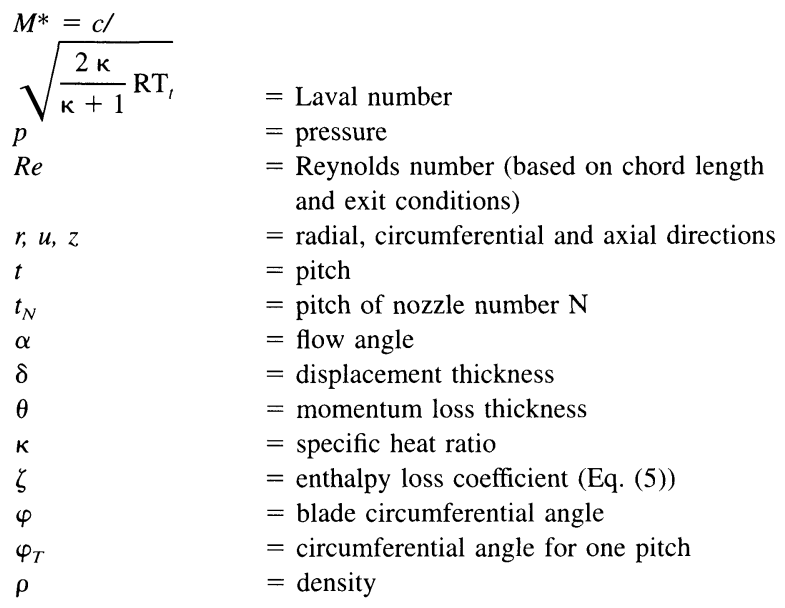

subscripts

$\begin{array}{ll}h, s & =\text { hub }, \text { shroud } \\ m & =\text { mid-span } \\ r, u, z & =\text { radial, circumferential and axial directions } \\ s & =\text { isentropic } \\ t & =\text { total } \\ w, i, n & =\text { wide, intermediate and narrow nozzle } \\ 0 & =\text { inlet measuring plane } \\ l & =\text { exit measuring plane }\end{array}$

superscripts

$\begin{array}{ll}- & =\text { averaged over pitch } \\ = & =\text { circumferential average }\end{array}$

\section{References}

Arndt, N., 1991, "Blade Row Interaction in a Multistage Low-Pressure Turbine”, ASME paper No. 91-GT-283.

Dejc, M.E., Trojanovskij, B.M., 1973, Untersuchung und Berechnung axialer Turbinenstufen, VEB Verlag Technik, Berlin.

Gloger, M., 1979, Experimentelle Untersuchung der durch die benachbarten Schaufelgitter hervorgerufenen instationaeren Kraefte auf die Laufschaufeln von Axialturbinen, Diss. Univ. Stuttgart.

Korakianitis, T., 1993, "On the Propagation of Viscous Wakes and Potential Flow in Axial Turbine Cascades", ASME Journal of Turbomachinery, Vol. 115, pp. 118-127.

Kurz, R., 1991, Experimentelle und theoretische Untersuchungen an gleichfoermig und ungleichfoermig geteilten Turbinengittern, $\mathrm{PhD}$ Thesis, Univ. of the German Armed Forces, Hamburg.

Kurz, R., 1992, "Transonic Flow Through Turbine Cascades with Nonuniform Pitch”, ASME Paper No. 92-GT-158. 

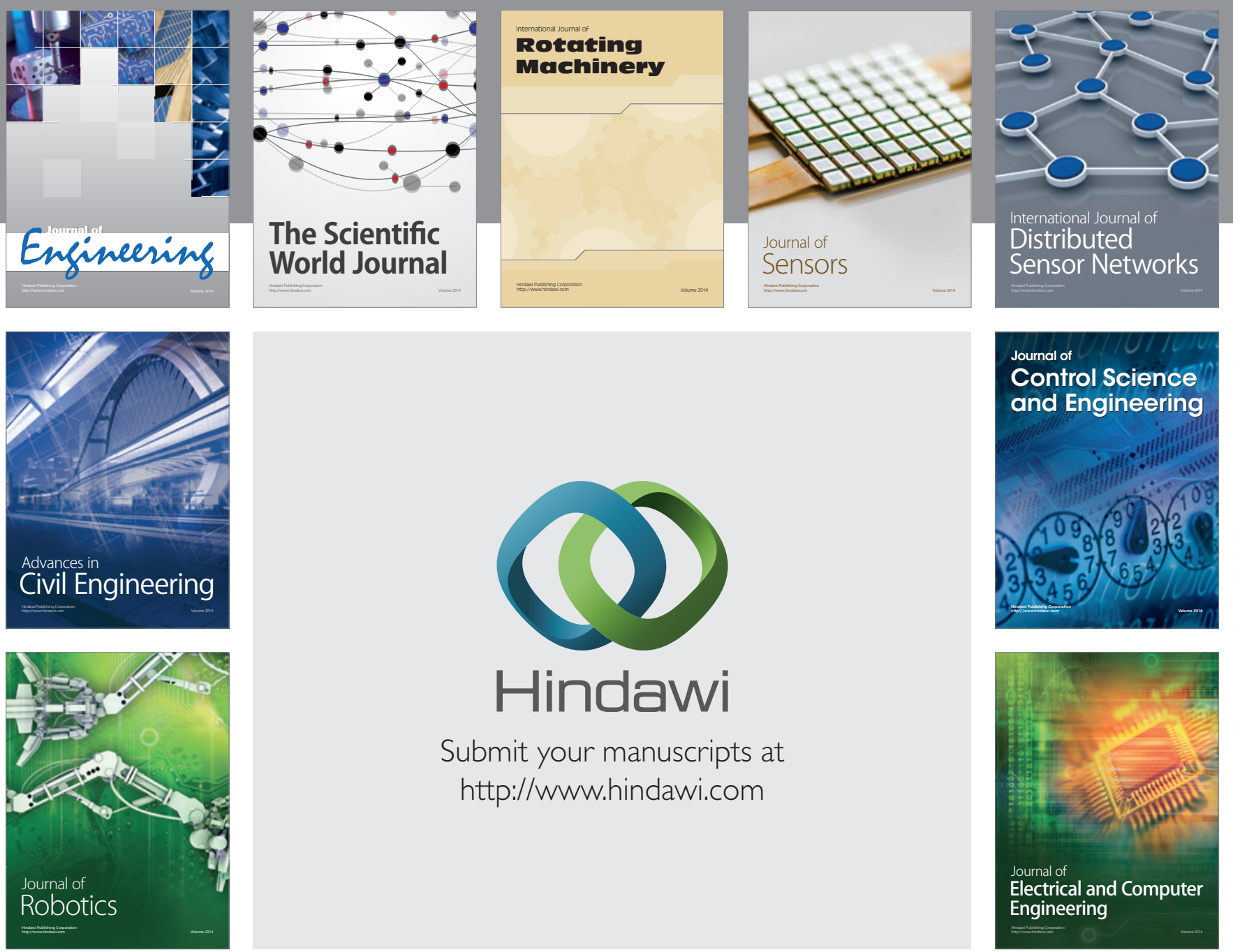

Submit your manuscripts at

http://www.hindawi.com
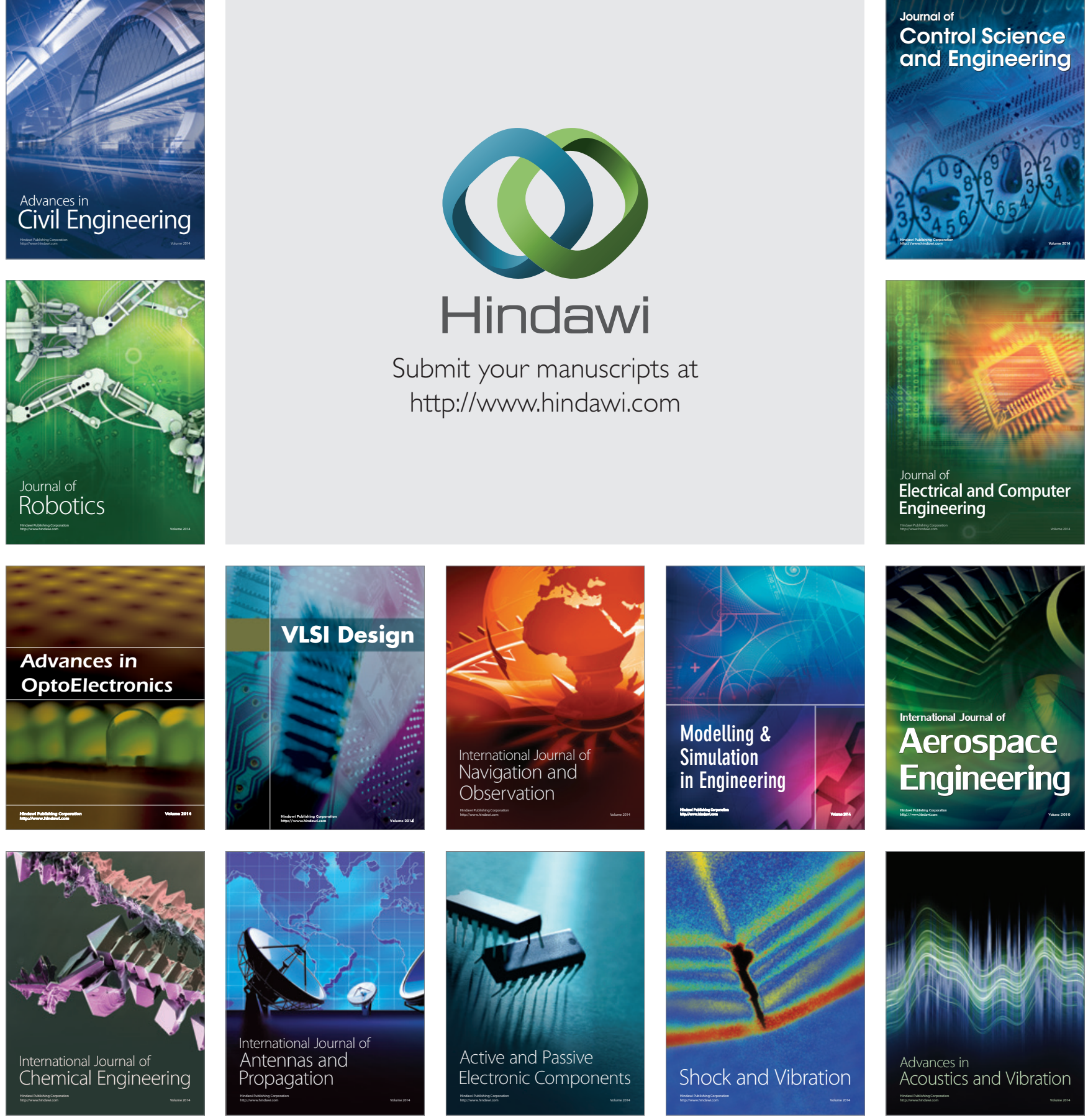